\title{
Optimal design and patient selection for interventional trials using radiogenomic biomarkers: A REQUITE and Radiogenomics consortium statement
}

Citation for published version (APA):

De Ruysscher, D., Defraene, G., Ramaekers, B. L. T., Lambin, P., Briers, E., Stobart, H., Ward, T., Bentzen, S. M., Van Staa, T., Azria, D., Rosenstein, B., Kerns, S., \& West, C. (2016). Optimal design and patient selection for interventional trials using radiogenomic biomarkers: A REQUITE and Radiogenomics consortium statement. Radiotherapy and Oncology, 121(3), 440-446.

https://doi.org/10.1016/j.radonc.2016.11.003

Document status and date:

Published: 01/12/2016

DOI:

10.1016/j.radonc.2016.11.003

Document Version:

Publisher's PDF, also known as Version of record

Document license:

Taverne

Please check the document version of this publication:

- A submitted manuscript is the version of the article upon submission and before peer-review. There can be important differences between the submitted version and the official published version of record.

People interested in the research are advised to contact the author for the final version of the publication, or visit the DOI to the publisher's website.

- The final author version and the galley proof are versions of the publication after peer review.

- The final published version features the final layout of the paper including the volume, issue and page numbers.

Link to publication

\footnotetext{
General rights rights.

- You may freely distribute the URL identifying the publication in the public portal. please follow below link for the End User Agreement:

www.umlib.nl/taverne-license

Take down policy

If you believe that this document breaches copyright please contact us at:

repository@maastrichtuniversity.nl

providing details and we will investigate your claim.
}

Copyright and moral rights for the publications made accessible in the public portal are retained by the authors and/or other copyright owners and it is a condition of accessing publications that users recognise and abide by the legal requirements associated with these

- Users may download and print one copy of any publication from the public portal for the purpose of private study or research.

- You may not further distribute the material or use it for any profit-making activity or commercial gain

If the publication is distributed under the terms of Article 25fa of the Dutch Copyright Act, indicated by the "Taverne" license above, 
Rediogenomics

\title{
Optimal design and patient selection for interventional trials using radiogenomic biomarkers: A REQUITE and Radiogenomics consortium statement
}

\author{
Dirk De Ruysscher ${ }^{\mathrm{a}, \mathrm{b}, *}$, Gilles Defraene ${ }^{\mathrm{b}}$, Bram L.T. Ramaekers ${ }^{\mathrm{c}}$, Philippe Lambin ${ }^{\mathrm{a}}$, Erik Briers ${ }^{\mathrm{d}}$, \\ Hilary Stobart ${ }^{\mathrm{e}}$, Tim Ward ${ }^{\mathrm{f}}$, Søren M Bentzen ${ }^{\mathrm{g}}$, Tjeerd Van Staa ${ }^{\mathrm{h}}$, David Azria ${ }^{\mathrm{i}}$, Barry Rosenstein ${ }^{\mathrm{i}}$, \\ Sarah Kerns ${ }^{\mathrm{j}}$, Catharine West ${ }^{\mathrm{k}}$
}

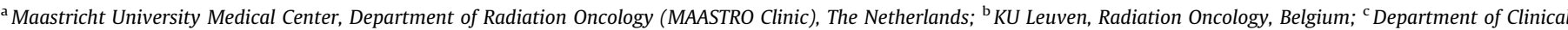

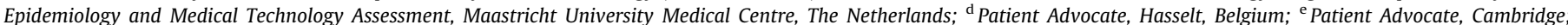

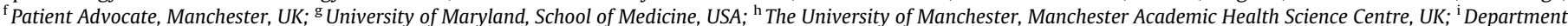

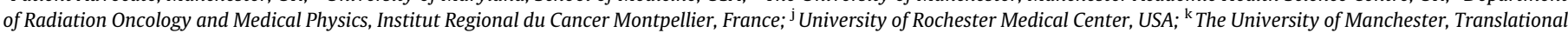
Radiobiology Group I Institute of Cancer Sciences, The Christie NHS Foundation Trust, UK

\section{A R T I C L E I N F O}

\section{Article history}

Received 17 September 2016

Received in revised form 25 October 2016

Accepted 1 November 2016

Available online 12 December 2016

\section{Keywords:}

Trial design

Patient selection

Radiogenomics

Biomarkers

\begin{abstract}
A B S T R A C T
The optimal design and patient selection for interventional trials in radiogenomics seem trivial at first sight. However, radiogenomics do not give binary information like in e.g. targetable mutation biomarkers. Here, the risk to develop severe side effects is continuous, with increasing incidences of side effects with higher doses and/or volumes. In addition, a multi-SNP assay will produce a predicted probability of developing side effects and will require one or more cut-off thresholds for classifying risk into discrete categories. A classical biomarker trial design is therefore not optimal, whereas a risk factor stratification approach is more appropriate. Patient selection is crucial and this should be based on the dose-response relations for a specific endpoint. Alternatives to standard treatment should be available and this should take into account the preferences of patients. This will be discussed in detail.
\end{abstract}

(c) 2016 Elsevier Ireland Ltd. All rights reserved. Radiotherapy and Oncology 121 (2016) 440-446

\section{Introduction}

Radiotherapy is used to treat more than $50 \%$ of cancer patients with either curative or palliative intent. In general, there is an assumed dose-effect relationship for local tumour control [1], i.e., higher radiation doses increase the probability of local tumour control. However, the risk of late side effects hampers dose escalation, and so-called "tolerance" doses to organs at risk (OAR) have been determined as those considered acceptable. Typically, a 5$10 \%$ chance of developing side effects with a severity of grade 3 or more is regarded as "acceptable". This is of course a subjective percentage. Some patients may consider a higher probability of side effects acceptable to achieve an increased probability for cure, whereas others might favour a lower risk of side effects despite a reduced probability for cure. Moreover, the level of risk considered acceptable also depends on the type of side effect [1,2].

Currently, comparable patients with a similar type and stage of disease receive the same radiotherapy regimen (dose and fraction-

\footnotetext{
* Corresponding author at: MAASTRO Clinic, University Maastricht, GROW Research Institute, Dr. Tanslaan 12, 6229 ET Maastricht, The Netherlands.

E-mail address: dirk.deruysscher@maastro.nl (D. De Ruysscher).
}

ation schedule), with adjustments made according to dose and volume parameters of the organs at risk [3,4]. The ability to predict an individual's risk of side effects would enable an informed decision and a move to personalised treatments [5]. Such treatment individualisation requires predictive models that are accurate enough to estimate a risk percentage for a certain side effect and its grade for each individual patient. Unfortunately, this is not the case for existing predictive models. Most models are essentially based on dose-volume parameters, with some including a few clinical factors, and have an area under the curve (AUC) of less than 0.70 [3]. However, they are often used in clinical practice to set the "threshold doses" for OAR because of their high negative predictive value (NPV), typically above 0.80 . This "threshold" is set conservatively in order to achieve a low proportion of patients experiencing severe side effects. The consequence is that most patients could receive a higher radiation dose and hence theoretically a better probability of local tumour control without undue toxicity while the same "acceptable" proportion of individuals develop severe side effects. This concept has been used in individualised "isotoxic" radiotherapy schedules [4]. 
More recently, studies have revealed a role for genetic variation in influencing response to radiotherapy [5]. The field of "radiogenet ics/genomics" investigates the relationships between the genes/ biologic pathways involved in cellular/tissue responses to radiation and risk of radiotherapy toxicity. In the future, this will lead to the development of risk models that can be used to stratify patients according to their genetic risk for radiotherapy-induced damage and hence to more optimal personalised radiotherapy schedules [6]. Radiogenomic studies have already identified loci that influence late radiation damage, such as those in TANC1 [7]. It is very likely that in the coming years, many genetic variants will be identified that individually contribute small increased risks for radiation damage, but together represent an actionable polygenic risk profile of sensitivity. These radiogenomic profiles would be used in combination with physical and clinical parameters to increase the accuracy of models predicting radiation toxicity. Targets that are suitable for a therapeutic intervention may be identified as well.

Radiogenomic models including genetic, physical and clinical parameters would underpin future personalised/precision radiotherapy. However, prior to clinical implementation these new models would need to be validated in clinical trials to test whether they can improve outcomes for patients [8]. In the past, models have mainly been developed and tested on retrospective series and few if any have passed the criteria for biomarker validation and implementation [9].

With an increasing number of predictive models being published it is of interest to consider if there could be an optimal design for testing whether they have a clinical impact. This review, therefore, considers possible interventions, endpoints and trial designs for testing the benefit of predictive models of radiotherapy toxicity. The design should be not only scientifically sound and practice changing, but also acceptable to patients. For that reason, patient representatives were invited to contribute to this work.

\section{Interventions}

Interventions that can be considered are: alternative treatment dose modification, altered radiotherapy, mitigation/amelioration and the omission of postoperative radiotherapy in patients with a low risk for tumour recurrence.

For some cancers, there can be a choice of surgery or radiotherapy. An example, for breast cancer patients where those identified as having a high risk of toxicity could consider a mastectomy versus a breast conserving lumpectomy followed by radiotherapy. Surgery versus organ preserving radiotherapy can also be an option for some prostate and bladder cancers. Of course important questions remain about the relationships between susceptibility for normal tissue damage following surgery and radiotherapy. It is possible that some individuals have a high susceptibility to damage irrespective of the type of treatment. It is assumed that toxicities with the strongest radiation dose response relationship will be more specific for radiotherapy, but we are not aware of any evidence to support or refute this suggestion. For some cancer types, the toxicity profile may differ depending on the treatment type, and this could be a deciding factor in selecting the optimal treatment.

Individualised dose prescriptions could be considered. Perhaps the preferred option here would be dose escalation in those identified as having a very low risk of toxicity. However, elderly patients with cancers with poor overall survival rates, e.g., lung cancers, might choose palliative rather than potentially curative regimens.

Altered radiotherapy could be considered, such as hyperfractionation that can reduce toxicity for equivalent local control
[10]. With the availability of stereotactic radiotherapy and increasingly proton therapy, defined patient groups at risk for toxicity based on their genetic profile and not only on dosimetric parameters $[11,12]$ may be considered for these modalities.

Another option is for a therapeutic intervention. This may include radio-protectors (agents that reduce the incidence and/or the severity of acute and/or late toxicity as they reduce the initial extent of normal tissue damage) or radiation mitigators (agents that act after radiotherapy has been given but prior to the manifestation of toxicity) [13]. The largest amount of data comes from trials with amifostine, a thiol that scavenges free radicals. Although amifostine is the only FDA-approved radio-protector and that some trials did show a slight reduction of side effects, it is not widely used because there remains doubt about potential protection of the tumour as well. Moreover, neither amifostine nor newer radio-protectors have been tested in selected patients at high risk for radiation injury, e.g. identified by their radio-genomics profile [14]. As will be discussed later, the selection of the appropriate patients is essential to study radio-protectors or -mitigators. As many patients are treated with concurrent chemotherapy and radiotherapy, protectors and mitigators should also be investigated in this setting.

Adjuvant radiotherapy is frequently applied in, for instance, patients with breast or prostate cancer, aiming to diminish the chance of local recurrence. In breast cancer, postoperative radiotherapy decreases the chance of local recurrence by $50 \%$ and increases the survival by one sixth [15]. However, the absolute benefit differs greatly between the risk groups, with the lowest risk group only showing an increase in 15 -year survival of $0.1 \%$. Also in prostate cancer, postoperative radiotherapy improved the clinical progression-free survival at 5-years, but only in subgroups of patients [16]. Patients with a low risk of local recurrence but with a higher risk for toxicity could be omitted from postoperative radiotherapy.

\section{Endpoints}

The selection of the appropriate endpoints for clinical trials is essential. For interventional trials using radio-genomic biomarkers, this is difficult. Both acute and late radiotherapy toxicity have profound effects on the quality of life of cancer patients, particularly when the toxicity is severe $[1,2]$. Acute toxicity in one organ (e.g. the oesophagus) does not predict late damage in another site (e.g. the lung), but late consequential damage bridges acute and late toxicity in the same organ $[17,18]$. In clinical studies a primary endpoint may need to involve multiple toxicities occurring at different time-points. Statistical methods have been developed for this purpose $[19,20]$. Not only toxicity, but also quality of life, local control and survival following any intervention must be taken into account. Recommendations for the reporting of radio-genomics research were described in the STROGAR guidelines and should be addressed [21]. Surrogate endpoints for late radiation damage would increase the speed of the assessment, but these are not validated at present $[22]$.

There is clearly no simple endpoint or time point that can be selected when designing a clinical trial. Composite endpoints should be considered.

\section{Study designs}

\section{Randomised clinical trials}

Randomised clinical trials (RCTs) are frequently considered to be the gold standard to obtain level I clinical evidence for interventional studies $[23,24]$. RCTs control for heterogeneity of the participants and allocation bias to a certain treatment arm, and because 
of the control arm, the true assessment of the predictive value of a model can be statistically determined.

RCTs are thus appropriate designs when it comes to validate predictive models aiming to stratify patients: (1) most likely to benefit from standard dose radiotherapy; (2) likely to be at increased risk for an adverse reaction to radiotherapy; and (3) likely to benefit from an intervention [23].

Theoretically, four randomised designs are most applicable to test radio-genomic models in an RCT, although ten possible designs have been described [24]. The most important RCT designs are:

\section{a: Randomize-all design}

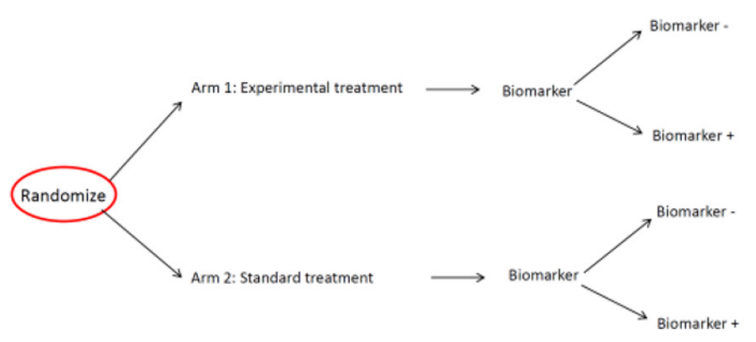

\section{b: Interaction or a risk-factor stratified design}

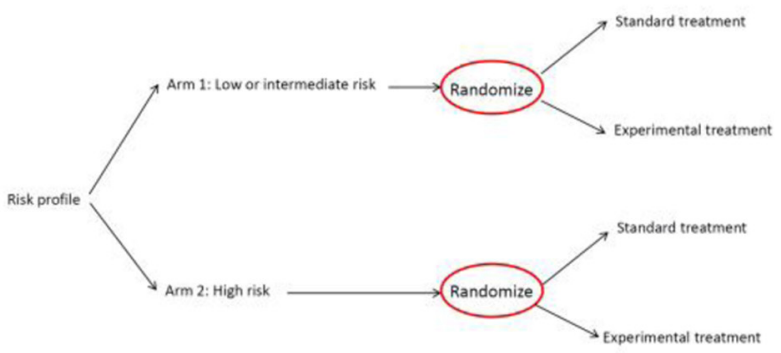

c: Targeted or selected design

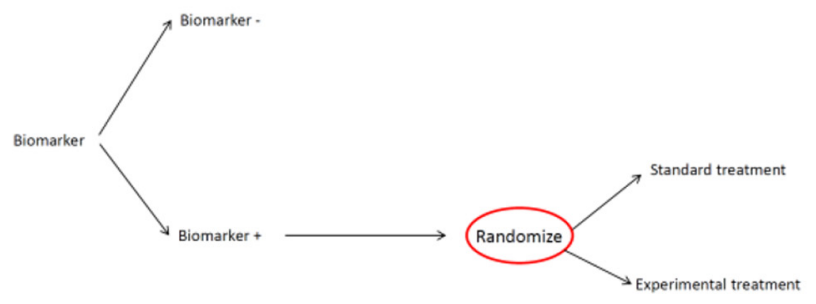

d: Individual profile design

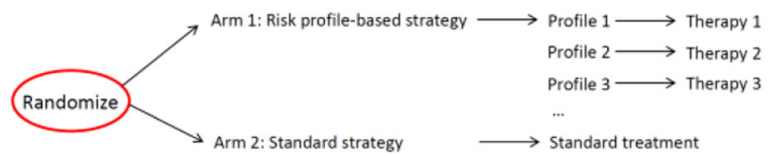

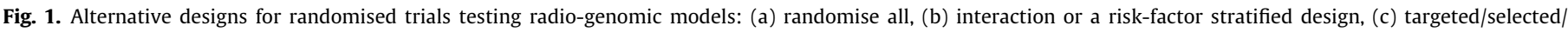
enriched design and (d) individual profile design. 
randomise-all, interaction or risk factor-stratified design, targeted or selection design and the individual profile design (Fig. 1a-d). The randomise-all design is straightforward, and may be optimal because the risk groups can be validated without harming the patient (Fig. 1a). In the interaction or risk-factor stratified design, the patients are first tested for their toxicity risk and subsequently stratified into for example two groups: a high-intermediate risk group and a low risk group (Fig. 1b). Subsequently, patients are randomised in a standard and an experimental arm. This design enables hierarchical statistical tests.

A predictive model should ideally indicate benefit from a particular intervention as models that indicate risks with no treatment recommendation are unlikely to have a clinical impact. However such models are useful in validating possible biomarker applica- tions, which in other trials may have clinical impact. However, in contrast to a biomarker such as a targetable mutation with a binary outcome (biomarker present or not), radio-genomic based models just like DVH parameters give probabilities for a certain side effect. Trials that stratify according to risk groups are therefore more suitable for radio-genomic studies.

Models could be used to identify an enriched population in which only patients identified as having a high risk of toxicity are randomised. In targeted/selected/enriched designs, patients are first tested and afterwards randomised to standard therapy or an experimental arm (Fig. 1c). This approach increases the statistical power and tests the efficacy of an intervention even when the confidence in the accuracy of the model is low [24].

\section{A: Radiation pneumonitis}

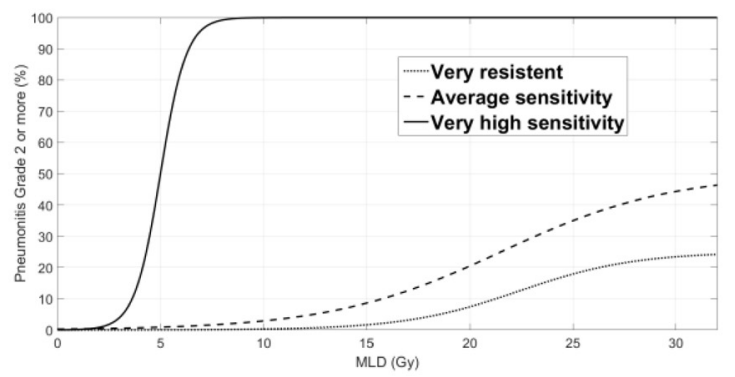

\section{B: CT-measured lung fibrosis (tumour dose reduction from $60 \mathrm{~Gy}$ to $50 \mathrm{~Gy}$ )}

\section{Upper to lower panel: Resistant, Average sensitivity, Sensitive}
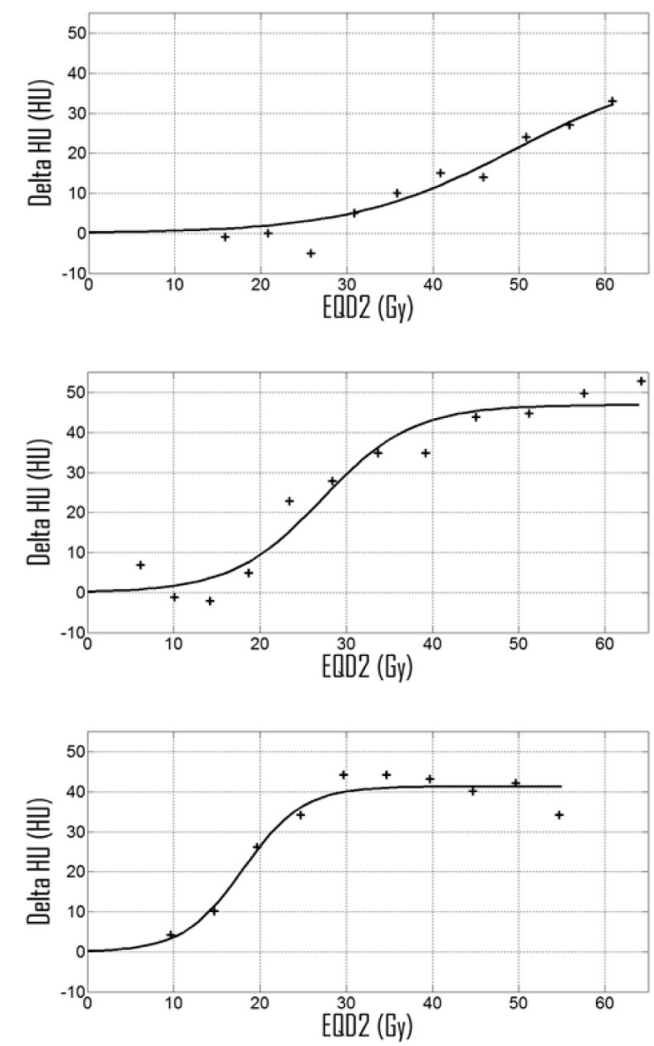

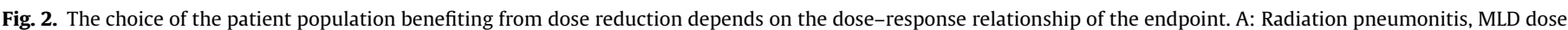

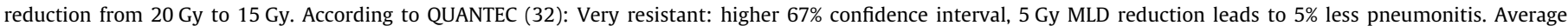

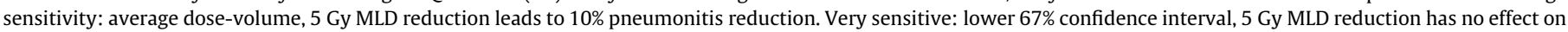

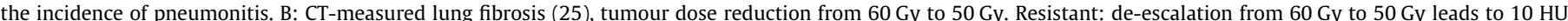

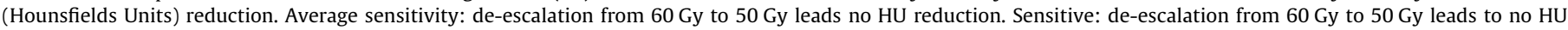
reduction. 
Table 1

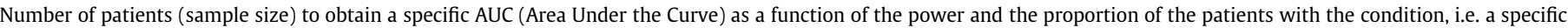
genetic feature that is related to radio-sensitivity.

\begin{tabular}{|c|c|c|c|c|c|c|}
\hline \multirow{3}{*}{ Total sample size } & \multirow{3}{*}{ Power $=$} & \multicolumn{5}{|l|}{$90,0 \%$} \\
\hline & & AUC & & & & \\
\hline & & 0,75 & 0,80 & 0,85 & 0,90 & 0,95 \\
\hline \multirow[t]{16}{*}{$\%$ with condition } & $5 \%$ & 6875 & 6386 & 5482 & 4031 & 1991 \\
\hline & $10 \%$ & 3576 & 3306 & 2825 & 2069 & 1018 \\
\hline & $15 \%$ & 2486 & 2289 & 1946 & 1419 & 696 \\
\hline & $20 \%$ & 1952 & 1788 & 1513 & 1098 & 535 \\
\hline & $25 \%$ & 1640 & 1495 & 1259 & 910 & 440 \\
\hline & $30 \%$ & 1442 & 1307 & 1095 & 786 & 379 \\
\hline & $35 \%$ & 1309 & 1182 & 985 & 703 & 337 \\
\hline & $40 \%$ & 1222 & 1095 & 907 & 644 & 307 \\
\hline & $45 \%$ & 1165 & 1039 & 855 & 604 & 286 \\
\hline & $50 \%$ & 1134 & 1006 & 822 & 576 & 270 \\
\hline & $55 \%$ & 1126 & 991 & 806 & 560 & 262 \\
\hline & $60 \%$ & 1142 & 999 & 805 & 557 & 257 \\
\hline & $65 \%$ & 1183 & 1028 & 823 & 563 & 257 \\
\hline & $70 \%$ & 1259 & 1086 & 863 & 585 & 265 \\
\hline & $75 \%$ & 1384 & 1186 & 934 & 627 & 280 \\
\hline & $80 \%$ & 1592 & 1353 & 1055 & 702 & 309 \\
\hline
\end{tabular}

The individual profile design allows inclusion of a large number of different profiles (Fig. 1d). Although this design is at first glance attractive and reflects the needs for individualised medicine, it tends to be inefficient in comparing the efficacy difference of two treatments as patients in different randomised arms are treated with the same therapy [24].

Although the strengths of the RCT are clear, it has been questioned whether it is the most appropriate in all situations. Side effects of radiotherapy may appear after many years or even decades in patients that were treated with outdated techniques, hampering a classical trial design and follow-up. Surrogate endpoints for late toxicity may be required to investigate the efficiency of new radiotherapy techniques or novel agents that mitigate or prevent radiotherapy toxicity.

\section{Retrospective observational study}

The most frequently used alternative to a RCT is a case-control study, which is an observational study. Almost all common variants associated with common traits in genetic studies have been detected in case-control or cohort studies, which are another type of observational study. A case-control study can be constructed from an observational cohort study, also known as a nested case-control study. In the case-control approach, patients are enrolled according to their phenotype or response. Both response and genotype data are required as well as details of radiotherapy and clinical features such as diabetes. This design enables control of the recruitment sample size of both the cases and the controls.

Observational studies thus allow patient stratification according to their risk of developing toxicity following radiotherapy. Such studies can identify risk factors (including genetic) for radiotherapy toxicity, and allow other questions to be addressed, e.g., is there a correlation between the susceptibility of OARs for radiation damage and that of the tumour. However, there remains a need for independent, prospective validation to show the accuracy of any predictive model. As in an RCT, the long follow-up times for late effects would however remain a problem for prospective validation in observational studies. There is also a need for an 'intervention' to test whether a model predicts benefit from a particular radiotherapy dose/schedule and what the therapeutic consequences are.

Observational studies carry a risk of confounding: a certain genotype or phenotype may be associated with more aggressive tumours and the apparent presence of more damage, though this could be investigated and controlled for in analysis. The best approach may then be to tailor radiotherapy to tumour stage rather than to the genotype or phenotype. Furthermore, an observational study that does find an increase of radiotherapy-induced damage with a certain dose may not provide an answer of what dose to use instead.

\section{How good should the model be?}

It is hard to determine how precise a predictive model should be to be informative. Imprecise models need a "conservative" threshold to obtain a reasonable NPV to be useable. As model precision improves, thresholds can be relaxed, e.g., a very precise model could select patients for receiving a higher radiation dose with no risk of undue toxicity. Although more precise models will typically result in more benefit, less precise models might be informative to some degree.

Estimations of precision are uncertain, classically expressed by confidence intervals $(\mathrm{CI})$. The estimated risk may therefore be less revealing for a patient than it may seem, e.g. if the risk for severe toxicity is $25 \%$, but with a $95 \%$ confidence interval $(\mathrm{CI})$ ranging from $11 \%$ to $47 \%$, the patient is less able to make an informed choice than with a smaller CI. The $95 \%$ CI between the different treatment options should therefore be minimised and preferably not overlapping. Quantitative differences between the treatment options should be clear.

The consequences of the incidence of toxicity/toxicities on the number of patients needed for prospective validation as a function of the prevalence of a genetic profile must be considered (Table 1). For example, a radio-genomics model with an AUC of 0.95 but including common genetic variants with a prevalence of only $5 \%$ requires a study of 1488 patients ( 0.80 power). If the genetic variants are prevalent in $35 \%$ of the patients, 252 patients are needed. In practice, a polygenic risk score will likely be needed as individual genetic variants each contribute only modestly to risk of developing toxicity. A clear view on the different parameters and the expected performance of the model is therefore necessary to avoid an underpowered interventional study. Large observational studies can be useful in improving precision of risk estimates and model performance parameters in anticipation of interventional studies.

\section{Identification of patient groups that could benefit most from a radio-genomic biomarker}

Decreasing the standard radiation dose in the most susceptible patients is highly dependent on the dose-effect relationship as 
illustrated in Fig. 2. In a realistic dose reduction scenario of the mean lung dose (MLD) e.g. by proton therapy from $20 \mathrm{~Gy}$ to $15 \mathrm{~Gy}$ [25], this would reduce the incidence of important radiation pneumonitis only marginally by $5 \%$ in resistant patients, by $10 \%$ in patients with an average radio-sensitivity and not at all in patients who are very sensitive (Fig. 2, [26]. If CT-density changes as a measure of fibrosis are used [27] and the tumour dose reduced from $60 \mathrm{~Gy}$ to $50 \mathrm{~Gy}$, in resistant patients this would lead to a fibrosis reduction by an absolute amount of $10 \mathrm{HU}$ for lung tissue close to the tumour, whereas no reduction would be observed in average or sensitive individuals.

A patient group who could potentially benefit greatly from a radio-genomic biomarker is that for which there already exist potential preventive interventions. For example, a recent clinical trial among prostate cancer patients showed that preradiotherapy use of a hydrogel spacer injected between the prostate and rectum reduced the incidence of late (3-15 month) rectal toxicity from $7.0 \%$ in the control arm to $2.0 \%$ in the treatment arm [28]. Because the hydrogel spacer must be placed prior to the start of radiotherapy, a large proportion of patients who would not have gone on to develop toxicity were subjected to an additional procedure and associated costs. Indeed, a cost-effectiveness decision analysis based on the results of this trial reported that use of a rectal spacer for conformal RT results in a small cost increase after accounting for costs associated with placement of the spacer and savings associated with reduction of treatment of toxicity [29]. A radio-genomic biomarker capable of identifying the minority of patients at high risk for rectal toxicity could select for the group most likely to benefit from use of a hydrogel spacer, thus reducing cost, procedure time, and inconvenience to the overall patient population.

An in-depth knowledge of the dose-volume relation for a specific endpoint taking into account the clinical usefulness of the dose reduction is needed in order to select the correct patient for this strategy.

\section{Patient considerations}

For the results of a study to be of value for patients, there should be a therapeutic alternative for the standard of care radiotherapy and the quantitative gain should be measurable and relevant. The incidence of peak reactions after radiotherapy is not the only parameter that should be taken into account. It is their severity, reversibility, the possible salvage treatments and the overall influence on quality of life that is also crucial to take into account. Patients deemed high risk of toxicity could also be monitored more closely and for a longer period of follow up. Understanding and communicating all of this, including their uncertainties, is a typical field for shared decision-making, which should be part of all radiogenomic trials [30-36].

\section{Conclusions}

Many theoretical designs are possible for trials involving radiogenomic biomarkers, all of which have their advantages and disadvantages. Depending on the question of the study and whether or not an intervention is studied, retrospective observational studies up to randomised phase III trials may be the most appropriate. Patient selection is crucial and this should be based on the doseresponse relations for a specific endpoint. Alternatives to standard treatment should be available and this should take into account the preferences of patients. Many patient related outcomes, including quality of life, are appropriate as endpoints.

\section{Conflict of interest statement}

None of the authors have a conflict of interest to declare.

\section{Acknowledgement}

This project has received funding from the European Union's Seventh Framework Programme for research, technological development and demonstration under grant agreement no 601826 (REQUITE).

SK received a career development award (K07CA187546) from the National Cancer Institute in the USA.

\section{References}

[1] Marks LB, Bentzen SM, Deasy JO, Kong FM, Bradley JD, Vogelius IS, et al. Radiation dose-volume effects in the lung. Int J Radiat Oncol Biol Phys 2010 Mar 1;76:S70-6.

[2] van Baardwijk A, Wanders S, Boersma L, Borger J, Öllers M, Dingemans AMC, et al. Mature results of an individualized radiation dose prescription study based on normal tissue constraints in stage I-III non-small cell lung cancer. J Clin Oncol 2010;28:1380-6.

[3] Kerns SL, West CM, Andreassen CN, Barnett GC, Bentzen SM, Burnet NG, et al. Radiogenomics: the search for genetic predictors of radiotherapy response. Future Oncol 2014 Dec;10:2391-406.

[4] Kerns SL, de Ruysscher D, Andreassen CN, Azria D, Barnett GC, Chang-Claude J et al. STROGAR - STrengthening the Reporting Of Genetic Association studies in Radiogenomics. Radiother Oncol 2014;110:182-8.

[5] Fachal L, Gómez-Caamaño A, Barnett GC, Peleteiro P, Carballo AM, CalvoCrespo $\mathrm{P}$, et al. A three-stage genome-wide association study identifies a susceptibility locus for late radiotherapy toxicity at 2q24.1. Nat Genet 2014;46 (8):891-4.

[6] Khoury MJ, Gwinn ML, Glasgow RE, Kramer BS. A population approach to precision medicine. Am J Prev Med 2012 Jun;42:639-45.

[7] Hall JA, Salgado R, Lively T, Sweep F, Schuh A. A risk-management approach for effective integration of biomarkers in clinical trials: perspectives of an $\mathrm{NCI}$ NCRI, and EORTC working group. Lancet Oncol 2014 Apr;15:e184-93.

[8] Guyatt GH, Oxman AD, Kunz R, Vist GE, Falck-Ytter Y, Schünemann HJ, et al. What is "quality of evidence" and why is it important to clinicians? BMJ 2008 May 3;336:995-8.

[9] Hoering A, Leblanc M, Crowley JJ. Randomized phase III clinical trial designs for targeted agents. Clin Cancer Res 2008;14:4358-67.

[10] Scaife JE, Barnett GC, Noble DJ, Jena R, Thomas SJ, West CM, et al. biomarkers in clinical trials. Expert Rev Mol Diagn 2011:11:171-82.

[11] Barnett GC, Kerns SL, Noble DJ, Dunning AM, West CM, Burnet NG. Incorporating Genetic Biomarkers into Predictive Models of Normal Tissue Toxicity. Clin Oncol (R Coll Radiol) 2015;27:579-87.

[12] Herskind C, Talbot CJ, Kerns SL, Veldwijk MR, Rosenstein BS, West CM. Radiogenomics: a systems biology approach to understanding genetic risk factors for radiotherapy toxicity? Cancer Lett 2016 Nov 1;382:95-109.

[13] Johnke RM, Sattler JA, Allison RR. Radioprotective agents for radiation therapy: future trends. Future Oncol 2014;10:2345-57.

[14] Andreassen CN, Schack LM, Laursen LV, Alsner J. Radiogenomics - current status, challenges and future directions. Cancer Lett 2016 Nov 1:382:127-36.

[15] Early Breast Cancer Trialists' Collaborative Group (EBCTCG), Darby S, McGale P, Correa C, Taylor C, Arriagada R, et al. Effect of radiotherapy after breastconserving surgery on 10-year recurrence and 15 -year breast cancer death: meta-analysis of individual patient data for 10,801 women in 17 randomised trials. Lancet 2011;378:1707-16.

[16] Bolla M, van Poppel H, Tombal B, Vekemans K, Da Pozzo L, de Reijke TM, et al. Postoperative radiotherapy after radical prostatectomy for high-risk prostate cancer: long-term results of a randomised controlled trial (EORTC trial 22911). Lancet 2012;380(9858):2018-27.

[17] Heemsbergen WD, Peeters ST, Koper PC, Hoogeman MS, Lebesque JV. Acute and late gastrointestinal toxicity after radiotherapy in prostate cancer patients: consequential late damage. Int J Radiat Oncol Biol Phys 2006;66:3-10.

[18] Kerns SL, Kundu S, Oh JH, Singhal SK, Janelsins M, Travis LB, et al. The prediction of radiotherapy toxicity using single nucleotide polymorphismbased models: a step toward prevention. Semin Radiat Oncol 2015;25:281-91.

[19] Darby SC, Ewertz M, McGale P et al. Risk of ischemic heart disease in women after radiotherapy for breast cancer. N Engl J Med 2013;368:987-98.

[20] Henson KE, McGale P, Taylor C, Darby SC. Radiation-related mortality from heart disease and lung cancer more than 20 years after radiotherapy for breast cancer. Br J Cancer 2013:108:179-82.

[21] Erven K, Florian A, Slagmolen P, Sweldens C, Jurcut R, Wildiers H, et al Subclinical cardiotoxicity detected by strain rate imaging up to 14 months after breast radiation therapy. Int J Radiat Oncol Biol Phys 2013 Apr $1 ; 85: 1172-8$.

[22] Rosen EM, Day R, Singh VK. New approaches to radiation protection. Front Oncol 2015;20:381. 
[23] Kraft P, Cox DG. Study designs for genome-wide association studies. Adv Genet 2008;60:465-504.

[24] SEARCH Collaborative Group, Link E, Parish S, Armitage J, Bowman L, Heath S, et al. SLCO1B1 variants and statin-induced myopathy - a genomewide study. N Engl J Med 2008;359:789-99.

[25] Roelofs E, Engelsman M, Rasch C, Persoon L, Qamhiyeh S, de Ruysscher D, et al. Results of a multicentric in silico clinical trial (ROCOCO): comparing radiotherapy with photons and protons for non-small cell lung cancer. J Thorac Oncol 2012:7:165-76.

[26] Tucker SL, Li M, Xu T, Gomez D, Yuan X, Yu J, et al. Incorporating singlenucleotide polymorphisms into the Lyman model to improve prediction of radiation pneumonitis. Int J Radiat Oncol Biol Phys 2013;85:251-7.

[28] Defraene G, van Elmpt W, Crijns W, Slagmolen P, De Ruysscher D. CT characteristics allow identification of patient-specific susceptibility for radiation-induced lung damage. Radiother Oncol 2015 Oct;117:29-35.

[29] Mariados N, Sylvester J, Shah D, Karsh L, Hudes R, Beyer D, et al. Hydrogel spacer prospective multicenter randomized controlled pivotal trial: dosimetric and clinical effects of perirectal spacer application in men undergoing prostate image guided intensity modulated radiation therapy. Int J Radiat Oncol Biol Phys 2015;92:971-7.

[30] Hutchinson RC, Sundaram V, Folkert M, Lotan Y. Decision analysis model evaluating the cost of a temporary hydrogel rectal spacer before prostate radiation therapy to reduce the incidence of rectal complications. Urol Oncol 2016;34(7). 291.e19-26.

[31] Spiegelhalter D, Pearson M, Short I. Visualizing uncertainty about the future Science 2011;333:1393-400.

32] Garcia-Retamero R, Galesic M. Who profits from visual aids? Overcoming challenges in people's understanding of risks. Soc Sci Med 2010;70:1019-25.

[33] Elwyn G, Lloyd A, Joseph-Williams N, Cording E, Thomson R, Durand MA, et al Option grids: shared decision making made easier. Patient Educ Counse 2013:90:207-12.

[34] Volk R, Llewellyn-Thomas H, Stacey D, Elwyn G. The International Patient Decision Aid Standards (IPDAS) Collaboration quality dimensions: theoretical rationales, current evidence, and emerging issues. BMC Med Inform Decision Making 2013:S1-S14.

[35] Lambin P, Zindler J, Vanneste BG, De Voorde LV, Eekers D, Compter I, et al Decision support systems for personalized and participative radiation oncology. Adv Drug Deliv Rev 2016. doi: http://dx.doi.org/10.1016/i. addr.2016.01.006. pii: S0169-409X(16)30008-4 [Epub ahead of print].

[36] Lambin P, Zindler J, Vanneste B, van de Voorde L, Jacobs M, Eekers D, et al Modern clinical research: How rapid learning health care and cohort multiple randomised clinical trials complement traditional evidence based medicine. Acta Oncol 2015;54:1289-300. 